\title{
Minor Groove Hydrogen-Bonds and the Replication of Unnatural Base Pairs
}

\author{
Shigeo Matsuda, Aaron M. Leconte, and Floyd E. Romesberg ${ }^{*}$ \\ Department of Chemistry, The Scripps Research Institute, 10550 N. Torrey Pines Road, La Jolla, \\ California, 92037
}

\begin{abstract}
As part of an effort to expand the genetic alphabet, we examined the synthesis of DNA with six different unnatural nucleotides bearing methoxy-derivatized nucleobase analogs. Different nucleobase substitution patterns were used to systematically alter the nucleobase electronics, sterics, and hydrogen-bonding potential. We determined the ability of the Klenow fragment of $E$. coli DNA polymerase I to synthesize and extend the different unnatural base pairs and mispairs under steady state conditions. Unlike other hydrogen-bond acceptors examined in the past, the methoxy groups do not facilitate mispairing, implying that they are not recognized by any of the hydrogen-bond donors of the natural nucleobases; however, they do facilitate replication. The more efficient replication results largely from an increase in the rate of extension of primers terminating at the unnatural base pair, and interestingly, requires that the methoxy group be at the ortho position where it is positioned in the developing minor groove and can form a functionally important hydrogen-bond with the polymerase. Thus, ortho methoxy groups should be generally useful for the effort to expand the genetic alphabet.
\end{abstract}

\section{Introduction}

An unnatural base pair that is stable and replicable would increase the biotechnological utility and information storage potential of DNA. ${ }^{1-5}$ Toward this goal, we have examined unnatural nucleotides that bear predominantly hydrophobic nucleobase analogs. ${ }^{6-14}$ These analogs are expected to pair with each other within duplex DNA via hydrophobic and packing interactions, but not with the natural nucleotides, due to forced desolvation of the more hydrophilic natural nucleobases. Our initial efforts focused on nucleobase analogs with large aromatic surface area and, along with other studies from the Hirao, $4,5,15$ Kuchta, ${ }^{16,17}$ Kool, ${ }^{18,19}$ and Berdis 20 , 21 labs, revealed that hydrophobic and packing forces were well suited to mediate base pair stability and polymerase-mediated synthesis (by insertion of the unnatural triphosphate opposite the unnatural nucleotide in the template). ${ }^{10-12}$ However, the utility of these unnatural base pairs has been consistently limited by insertion of the next correct dNTP (i.e. extension).

More recently, a significant improvement in extension rate has been achieved with several nucleobase analogs that have relatively little aromatic surface area. 6,9,22,23,25 Presumably, these pairs form a more natural-like primer terminus, as opposed to larger analogs that are likely to distort the primer terminus. While the BEN self pair (formed between two identical BEN analogs, Figure 1a) is not particularly stable ${ }^{24}$ or well recognized by DNA polymerases, 9 several derivatives have been identified that form self pairs or heteropairs (formed between

*To whom correspondence should be addressed. E-mail floyd@ scripps.edu.

floyd@ scripps.edu 
two different analogs) with significantly improved properties. For example, the $\mathbf{3 F B}, 6$ DM5, 9,24 and $\mathbf{T M}^{9,11,12,24}$ nucleotides (Figure 1a) form pairs that are reasonably stable and efficiently synthesized by the exonuclease deficient Klenow fragment of $E$. coli DNA polymerase I (Kf), but that are also extended with increased efficiency. Nonetheless, the extension of these pairs remains significantly less efficient than that of a natural base pair, and modifications that further increase extension rates are still required.

One possible reason for the poor extension of the predominantly hydrophobic base pairs is that, while optimized interbase packing may obviate the need for interbase hydrogen-bonds $(\mathrm{H}-$ bonds), ${ }^{26}$ efficient extension may require $\mathrm{H}$-bonding between the nucleobase at the primer terminus and the polymerase. ${ }^{19,27,28}$ Indeed, the natural nucleobases all have an H-bond acceptor oriented into the developing minor groove, and structural studies have revealed a conserved $\mathrm{H}$-bond between these acceptors at the primer terminus and polymerase based $\mathrm{H}$ bond donors, ${ }^{29}$ such as Arg668 in Kf. Biochemical studies have shown that extension is significantly reduced when these $\mathrm{H}$-bonds are disrupted. ${ }^{27,30}$ Thus, we have explored the derivatization of the phenyl-based nucleosides with either minor groove carbonyl groups 23 (by changing the $C$-nucleoside to an $N$-nucleoside) or minor groove nitrogen substituents that may act as H-bond acceptors. ${ }^{22}$ However, while these modifications increase extension rates, they also destabilize the base pair and appear to be recognized by the H-bond donor of dG, resulting in reduced thermal and replication fidelity.

To identify H-bond acceptors that may not be recognized by the natural nucleobases, but that could mediate important primer-polymerase interactions, we have begun to characterize phenyl-based nucleotides derivatized with methoxy groups. Based on both theory 31,32 and experiment, ${ }^{31-34}$ aryl methoxy groups should be capable of forming H-bonds, although strong H-bonds will only be possible when the methyl group is rotated out of the plane of the aryl ring, localizing electron density at the oxygen and making it a better H-bond acceptor. Indeed, thermodynamic studies of the same derivatives suggest that the methoxy groups are prone to desolvate upon duplex formation (S.M. and F.R. unpublished results). Thus, it is unclear whether these methoxy groups would engage the polymerase H-bond donors and align the primer terminus for efficient extension.

We now report a detailed characterization of the Kf-mediated synthesis and extension of the methoxy derivatized base pairs. The analogs characterized were designed to systematically explore the effects of methoxy groups at the ortho, meta, and/or para-positions (Figure 1b). Generally, we find that the addition of methoxy groups increases the selectivity of unnatural base pair synthesis, and when present at the ortho position, also have a selective and significant effect on extension, with some pairs being extended only $~ 100$-fold less efficiently than a natural base pair. Using the R668A mutant of $\mathrm{Kf}$, we show that this efficient extension requires the presence of the polymerase-based H-bond donor. The data suggest that an appropriately positioned methoxy group can productively engage the $\mathrm{H}$-bond donor of the DNA polymerase, which facilitates extension, but not the $\mathrm{H}$-bond donors of any natural nucleobase, which would stabilize or facilitate mispair formation.

\section{Results}

\subsection{Unnatural base pair synthesis efficiency}

The unnatural nucleotides were synthesized and converted into the corresponding phosphoramidites or triphosphates as described in Supporting Information. The phosphoramidites were used to synthesize template DNA containing the unnatural nucleotides at a single defined position. To begin to examine how methoxy groups impact polymerasemediated replication, we determined the steady-state rates with which Kf extends a primer terminating immediately $5^{\prime}$-to the unnatural base in the template by insertion of an unnatural 
triphosphate (Table 1). For reference, Kf inserts a natural dATP opposite dT with a second order rate constant (i.e. efficiency or $k_{\text {cat }} / K_{\mathrm{M}}$ ) of $1.7 \times 10^{8} \mathrm{M}^{-1} \mathrm{~min}^{-1}$. To compare the ability of nucleobases with either an ortho methyl or an ortho methoxy group to direct triphosphate insertion, we first examined the insertion of the unnatural triphosphates opposite either MM1 (Table 1, X = MM1) or 2OMe (Table 1, X = 2OMe). MM1 in the template directs unnatural base pair synthesis with second order rate constants (i.e. efficiency, $k_{\mathrm{cat}} / K_{\mathrm{M}}$ ) between $8.6 \times 10^{3}$ and $3.5 \times 10^{5} \mathrm{M}^{-1} \mathrm{~min}^{-1}$. Interestingly, methoxy substitution at the ortho position slightly decreases the rate of insertion of the more hydrophilic triphosphates, but increases the rate of insertion of the more hydrophobic triphosphates. The most efficiently synthesized pair results from the insertion of dTMTP opposite 2OMe, which proceeds with a second order rate constant of $7.0 \times 10^{5} \mathrm{M}^{-1} \mathrm{~min}^{-1}$. Because methoxy substitution increases the polarity of the nucleobase, the data suggest that, in addition to hydrophobic forces, specific structural and/or electrostatic interactions must contribute to base pair synthesis.

We next examined the effect of substituting methoxy groups for methyl groups within the DM5 scaffold in the template. This scaffold was chosen because of the relative stability and efficient replication of the DM5 self pair. The DM5 analog directs the insertion of the unnatural triphosphates with second order rate constants between $2.2 \times 10^{4}$ and $2.0 \times 10^{6} \mathrm{M}^{-1} \mathrm{~min}^{-1}$ (Table 1, X = DM5). Methoxy substitution of the template base (i.e. Table 1, X= MMO1 or MMO2) generally decreases the rates of unnatural triphosphate insertion, most so when the templating analog has two methoxy substituents (i.e. Table 1, X= DMO). With dMMO2TP the effects are slightly larger, and they are largest with dDM5TP. However, the opposite effect was observed with both dMM1TP and dTMTP, where changing the ortho substituent of the template analog from a methyl to a methoxy group increases the rate of unnatural triphosphate insertion. This data reinforces the conclusion that specific structural and/or electrostatic effects contribute to efficient unnatural base pair synthesis.

\subsection{Unnatural base pair synthesis fidelity}

To examine the synthesis of mispairs we determined the efficiencies with which Kf inserts natural dNTPs opposite the unnatural bases in the template (Table 2). dATP is consistently the most efficiently inserted natural triphosphate, with $k_{\text {cat }} / K_{\mathrm{M}}$ values falling between $5.5 \times 10^{4}$ $\mathrm{M}^{-1} \mathrm{~min}^{-1}$ and $1.8 \times 10^{5} \mathrm{M}^{-1} \mathrm{~min}^{-1}$. While this is more efficient than mispair synthesis among the natural nucleotides, 35 it is significantly less efficient than dATP insertion opposite any of the carbocyclic analogs MM1, MM2, MM3, or DM5 (which template dATP insertion with second order rate constants of $3.9 \times 10^{5}$ to $\left.2.9 \times 10^{6} \mathrm{M}^{-1} \mathrm{~min}^{-1}\right){ }^{9}$ After dATP, the next most efficiently inserted triphosphate is dTTP, with rates ranging from too slow to detect $\left(<10^{3}\right.$ $\mathrm{M}^{-1} \mathrm{~min}^{-1}$ ) to $2 \times 10^{3} \mathrm{M}^{-1} \mathrm{~min}^{-1}$, for insertion opposite 3OMe, MMO1 and DMO, or $3.2 \times$ $10^{4} \mathrm{M}^{-1} \mathrm{~min}^{-1}$, for insertion opposite 4OMe. Thus, dTTP insertion is strongly favored by para methoxy substitution, and disfavored by ortho methoxy substitution. dCTP is only inserted with a detectable rate opposite 3OMe, and dGTP is not detectably inserted opposite any of the analogs. Of particular interest is the selectivity against mispairing of the analogs, especially those with ortho methoxy H-bond acceptors (2OMe, MMO2 and DMO). The generally decreased rates with which the natural triphosphates are inserted opposite the methoxy derivatized analogs, relative to their fully carbocyclic counterparts, is surprising considering their decreased hydrophobicity, and this again suggests that specific structural and/ or electrostatic effects are important.

\subsection{Unnatural base pair extension efficiency}

To examine the contribution of methoxy groups to extension, we first examined the BEN nucleotide and nucleotides bearing single substituents at either the ortho, meta, or para positions of the phenyl nucleobase scaffold (Table 3). These analogs were incorporated into oligonucleotide templates and annealed to primers containing one of the analogs shown in 
Figure 1, resulting in the formation of an unnatural self pair or heteropair at the primer terminus. We determined the ability of $\mathrm{Kf}$ to extend each primer by incorporation of the next correct triphosphate (dCTP). For reference, a dA:dT pair is extended in the same sequence context with a $k_{\text {cat }} / K_{\mathrm{M}}$ of $1.7 \times 10^{8} \mathrm{M}^{-1} \mathrm{~min}^{-1}$. Pairs with BEN in the template were recognized poorly by Kf (Table 3, X = BEN). Only primers terminating with 2OMe, DMO, or MMO2 are extended with a detectable rate $\left(k_{\mathrm{cat}} / K_{\mathrm{M}}>1 \times 10^{3} \mathrm{M}^{-1} \mathrm{~min}^{-1}\right)$. Pairs formed with 2OMe in the template are extended poorly (Table $3, X=20 M e$ ), while pairs with either $30 \mathrm{Me}$ or $40 \mathrm{Me}$ in the template are extended between $1.5 \times 10^{4}$ and $4.8 \times 10^{4} \mathrm{M}^{-1} \mathrm{~min}^{-1}$, but again only when paired opposite 2OMe, DMO, or MMO2 at the primer terminus (Table 3, $\mathbf{X}=\mathbf{3 O M e}$ or 4OMe). This data suggests that an ortho methoxy group at the primer terminus facilitates extension.

We next examined the ortho, para di-substituted analogs MMO1, MMO2, and DMO in the template (Table 3). Kf does not efficiently recognize primers that terminate opposite MMO2 or DMO, regardless of the analog at the primer terminus (Table 3, X = MMO2 or DMO). In each case the second order rate constants are less than or equal to $1 \times 10^{4} \mathrm{M}^{-1} \mathrm{~min}^{-1}$. Also, most pairs involving MMO1 in the template are not well extended (Table 3, X= MMO1). However, the pairs formed with 2OMe, MMO2, or DMO in the primer and MMO1 in the template are again extended more efficiently, with second order rate constants of $\sim 1 \times 10^{5}$ $\mathrm{M}^{-1} \mathrm{~min}^{-1}$. This data reinforces the idea that ortho positioned methoxy groups at the primer terminus increase the rates of extension, but also suggests that the ortho methyl group of MMO1 in the template contributes to efficient extension, as well.

To further explore the effect of ortho methyl substituents in the template, the nucleobase analog MM1, DM5, or TM, was incorporated into the template strand (Table 3, X = MM1, DM5, or TM). Generally, the pairs formed with each of the primers are extended slightly better than the pairs without ortho methyl groups in the template analog, and the rates parallel the extent of methyl group substitution (TM > DM5 > MM1). Again, as with the mono-substituted analogs, the pairs formed with $2 \mathrm{OMe}$, DMO, or MMO2 in the primer are consistently extended more efficiently. In fact, the pairs formed between 2OMe, DMO, or MMO2 at the primer terminus and $\mathbf{T M}$ in the template are extended with rates between $3.2 \times 10^{5} \mathrm{M}^{-1} \mathrm{~min}^{-1}$ and 1.3 $\times 10^{5} \mathrm{M}^{-1} \mathrm{~min}^{-1}$. The MMO2:TM heteropair is extended $\sim 1000$-fold faster than the unsubstituted BEN self pair (which is extended with a rate of $1.6 \times 10^{3} \mathrm{M}^{-1} \mathrm{~min}^{-1}$ ) ${ }^{9}$ and only $\sim 100$-fold less efficiently than a natural base pair. The increased rates of extension of the 2OMe:TM, DMO:TM, and MMO2:TM heteropairs, relative to the BEN self pair, results from both increases in the apparent $k_{\mathrm{cat}}$ and decreases in the apparent $K_{\mathrm{M}}$. The data clearly reveal that unnatural base pair extension is facilitated both by an ortho methoxy group in the primer nucleobase and an ortho methyl group in the template nucleobase.

\subsection{Unnatural base pair extension fidelity}

To examine extension fidelity, we first characterized the rate at which $\mathrm{Kf}$ extends a primer terminating with dA paired opposite MMO1 or MMO2 (Table 4). To further elucidate the effect of the methoxy group substituent, primers terminating with dA paired opposite MM1, DM5, or TM were also characterized. The mispairs with dA at the primer terminus were examined because in each case, they are the most efficiently synthesized (see above). All mispairs except dA:MMO2 are extended by dCTP insertion with rates between $1.9 \times 10^{5}$ and $5.2 \times 10^{5} \mathrm{M}^{-1} \mathrm{~min}^{-1}$. In contrast, the dA:MMO2 mispair is extended less efficiently, with a $k_{\text {cat }} / K_{\mathrm{M}}$ of $4.6 \times 10^{4} \mathrm{M}^{-1} \mathrm{~min}^{-1}$. This rate is only marginally more efficient than the extension of a natural mispair, ${ }^{35}$ and demonstrates that the ortho methoxy group decreases the rate of mispair extension.

To further explore whether ortho methoxy groups at the primer terminus form mispairs with natural nucleotides that are recognized and extended by Kf, we paired 2OMe, DMO, or 
MMO2 opposite each natural nucleotide in the template and determined the efficiency of mispair extension (Table 4). None of the mispairs are extended efficiently, with rates varying from too low to detect $\left(<10^{3} \mathrm{M}^{-1} \mathrm{~min}^{-1}\right)$ to $2.6 \times 10^{4} \mathrm{M}^{-1} \mathrm{~min}^{-1}$. Interestingly, extension of the mispairs with $\mathrm{dG}$ is very inefficient. These results clearly demonstrate that an H-bond is not formed between guanine and the ortho methoxy substituent, or that if an $\mathrm{H}$-bond is formed, it does not contribute to a structure at the primer terminus that is recognized by Kf. In fact, the mispairs between either purine and the unnatural analogs are extended less efficiently than those with either pyrimidine. Because the purine mispairs are more structurally similar to a natural base pair, the more efficient extension of the pyrimidine mispairs is surprising.

\subsection{Primer-polymerase interactions and unnatural base pair extension}

To determine whether the minor groove methoxy groups facilitate unnatural base pair extension through formation of an $\mathrm{H}$-bond with the polymerase, we examined extension rates with the R668A mutant of $\mathrm{Kf}^{36}$ (Table 5). While other residues are also important for minor groove recognition of the primer terminus, ${ }^{36,37}$ Arg668 is the most thoroughly characterized, and among the identified residues, it has the largest effect during extension. Previous studies have shown that either removal of the H-bond donor from the polymerase (by mutation of Arg668 to Ala) or removal of the hydrogen bond acceptor from a natural nucleobase at the primer terminus (by substituting 3-deaza-dG for $\mathrm{dG}$ ) significantly decreases the rate of primer extension. ${ }^{27,30}$ Additionally, this mutant has been used to show that the difference in extension rates of two natural nucleobase analogs is due to H-bonding with the DNA polymerase. ${ }^{38} \mathrm{Kf}$ R668A extends the DM5:TM heteropair with a rate only 2-fold reduced from wild-type Kf, demonstrating that Arg668 does not form a functionally important H-bond with DM5. However, extension of the MMO2:TM heteropair is reduced 35-fold, to essentially the same rate as the DM5:TM heteropair. The apparent $K_{\mathrm{M}}$ increased almost 8-fold with MMO2 at the primer terminus, while it decreased 2-fold with DM5 at the primer terminus. In both cases, $k_{\text {cat }}$ decreased by approximately 4-fold. While it is difficult to interpret these changes mechanistically, as the kinetics are run under steady-state conditions, it is clear that removing the H-bond donor from the polymerase selectively decreases the extension efficiency of the pair with the minor groove methoxy group at the primer terminus. Thus, the ortho methoxy group of MMO2 appears to favorably interact with Arg668, presumably via H-bonding.

\section{Discussion}

Extension of unnatural base pairs by DNA polymerases generally limits their replication, and thus understanding how to facilitate extension is critical for developing viable unnatural base pairs. ${ }^{1}$ Previously, we examined phenyl-based nucleotides bearing H-bond acceptors that, when at the primer terminus, are expected to be oriented in the developing minor groove where they might engage a conserved polymerase-based H-bond donor. Specifically, we examined both minor groove carbonyl groups ${ }^{23}$ and nitrogen substituents. ${ }^{22}$ In addition, Hirao and coworkers have positioned an aldehyde group in the minor groove. $5,39,40$ While these modifications facilitate extension, they also destabilize the base pair and at least with the pyridone and pyridine nucleobases, appear to be recognized by the H-bond donor of dG, resulting in poor thermal and replication fidelity.

We are interested in nucleobase modifications that might facilitate H-bonding with the polymerase, but not with a natural nucleobase. Thermodynamic studies have indicated that when positioned ortho to the glycosidic linkage, methoxy groups are desolvated upon duplex formation (S.M. and F.R. unpublished results). This suggests that the H-bonding strength of the minor groove methoxy groups is insufficient to maintain solvation. Nonetheless, we were interested in examining whether these minor groove methoxy groups can engage the "preordered' H-bond donor of polymerases that is known to be required to align the primer terminus 
for efficient extension. Thus, we examined the effects of methoxy group substituents on polymerase-mediated replication.

Many previous studies have identified interbase hydrophobic interactions as a major force underlying the synthesis of pairs between different predominantly hydrophobic nucleobase analogs. ${ }^{4-6,10,11}$ Interestingly, the effects of substituting methoxy groups for methyl groups on unnatural base pair and mispair synthesis is not consistent with simple changes in hydrophobicity. For example, substitution of the ortho methyl group of MM1 with a methoxy group, to give 2OMe, results in the more efficient insertion of more hydrophobic triphosphate analogs, but less efficient insertion of more hydrophilic triphosphate analogs. In addition, 2OMe in the template is more selective against insertion of the more hydrophilic natural triphosphates than MM1. The effects can also be complex, for example, within the DM5 scaffold, a minor groove methoxy group slightly increases the rate of dMM1TP and dTMTP insertion, but significantly decreases the rate of dDM5TP insertion. These triphosphate analogs differ only by single methyl substituents, and the rates do not parallel the extent of substitution. In total, these results suggest that the methoxy substituents are capable of mediating specific structural and/or electrostatic effects that contribute to efficient unnatural base pair synthesis.

As discussed above, continued primer extension after synthesis of the unnatural base pair has traditionally limited the replication of DNA containing unnatural base pairs. We find that primers that terminate with a minor groove methoxy group paired opposite a template analog with a minor groove methyl group are efficiently extended. Remarkably, the MMO2:TM (primer:template) pair is extended only 100-fold slower than a natural base pair in the same sequence context. It is not obvious how the methyl group in the developing minor groove of the template analog contributes to efficient extension. However, the fact that mispairs with natural pyrimidines in the template are extended more efficiently than mispairs with purines suggests that the role of both the methyl group and the carbonyl group may be structural, perhaps helping to form a primer terminus that is optimally packed and structured for continued extension.

The effect of a minor groove methoxy group at the primer terminus is consistent and significant. For example, when paired opposite TM, MMO2 is extended more than 40-fold more efficiently than its carbocyclic analog DM5. Although this difference is less than the approximately 3500 -fold difference observed with $\mathrm{dG}$ and 3-deazaG, ${ }^{30}$ it is similar to that observed with other unnatural nucleobases where H-bond acceptors have been introduced. ${ }^{4}$, $19,22,23,39,40$ This suggests that while H-bonding between the primer terminus and the polymarase is important, other factors also contribute.

Methoxy groups of anisole are typically only moderate H-bond acceptors, as suggested by their $\mathrm{p} K_{\mathrm{a}}$ of $-6.5 .{ }^{41}$ However, both experimental and theoretical studies indicate that this is due in part to conjugation of the lone pairs of electrons on oxygen into the aromatic ring, which requires the methyl group to be in the plane of the ring. ${ }^{31-34}$ The same studies also indicate that when the methyl group rotates out of the plane, the electrons localize on the oxygen atom and it becomes a significantly better H-bond acceptor. Interestingly, molecular dynamics simulations suggest that the minor groove methyl groups of the unnatural base pairs rotate out of the plane of the phenyl ring to optimize packing interactions with flanking nucleobases (S.M and F.R. unpublished results). This, along with the 'pre-ordered' positioning of the polymerasebased H-bond donor, Arg668, appears to be sufficient to form a functional H-bond between the primer terminus and the polymerase. This conclusion is strongly supported by the selective decrease in R668A Kf-mediated extension efficiency of the MMO2:TM pair relative to the DM5:TM pair. The 'pre-ordering' of the Arg668 donor within the polymerase-DNA complex likely underlies the ability of the minor groove methoxy group to act as an H-bond acceptor despite its reduced ability to $\mathrm{H}$-bond with minor groove waters of solvation. 
It appears that an ortho positioned methoxy group is able to form a productive H-bond with the polymerase that appropriately aligns the primer terminus for continued extension. This, and the observation that these substituents do not increase mispair recognition or stability, as has been observed with other H-bond acceptors, 22,23 suggests that suitably positioned methoxy groups will be of great value in the design of new unnatural base pairs.

\section{Experimental Section}

\section{General Methods}

Chemical reagents were purchased from Sigma-Aldrich and used without further purification, unless otherwise stated. All unnatural nucleosides and nucleotides used in this study were synthesized as described in the Supporting Information. All reagents for oligonucleotide synthesis were purchased from Glen Research. Oligonucleotides were synthesized using an Applied Biosystems Inc. 392 DNA/RNA synthesizer. ${ }^{31} \mathrm{P}$ NMR spectra were recorded on a Bruker AMX-400 spectrometer. Coupling constants ( $\mathrm{J}$ values) are reported in $\mathrm{Hz}$. The chemical shifts are given in $\delta(\mathrm{ppm})$ using $85 \% \mathrm{H}_{3} \mathrm{PO}_{4}$ in $\mathrm{D}_{2} \mathrm{O}$ for ${ }^{31} \mathrm{P} \mathrm{NMR}$ as an external standard. $\mathrm{T} 4$ polynucleotide kinase and Klenow fragment exo- were purchased from New England Biolabs. $\left[\gamma_{-}{ }^{33} \mathrm{P}\right]$-ATP was purchased from Amersham Biosciences. The R668A/D424A double mutant of Kf was a generous gift from Catherine M. Joyce (Yale University). The D424A mutation renders the polymerase exonuclease deficient. For simplicity, the double mutant is referred to as the R668A mutant of the exonuclease deficient polymerase.

\section{Synthesis of oligonucleotides}

Oligonucleotides were prepared by the $\beta$-cyanoethylphosphoramidite method on controlled pore glass supports $(1 \mu \mathrm{mol})$ using an Applied Biosystems Inc. 392 DNA/RNA synthesizer as standard method. After automated synthesis, the oligonucleotides were cleaved from the support by conc. aqueous ammonia for $1 \mathrm{~h}$ at room temperature, deprotected by heating at 55 ${ }^{\circ} \mathrm{C}$ for $12 \mathrm{~h}$, and purified by denaturing polyacrylamide gel electrophoresis (12-20\%, $8 \mathrm{M}$ urea). The primer oligonucleotides containing unnatural bases at the 3 '-end were obtained using a Universal Support, or 3'-phosphate CPG, which was treated with alkaline phosphatase after deprotection according to manufacturer's protocols.

\section{General Triphosphate Synthesis Procedure}

Proton sponge (1.5 eq.) and nucleoside ( 1 eq.) were dissolved in trimethylphosphate (final concentration $\sim 0.3 \mathrm{M}$ ) and cooled to $0{ }^{\circ} \mathrm{C}$. $\mathrm{POCl}_{3}(1.05$ eq. $)$ was added dropwise and the mixture was stirred at $0{ }^{\circ} \mathrm{C}$ for $2 \mathrm{~h}$. Tributylamine ( 5 eq.) was added, followed by a solution of tributylammonium pyrophosphate (5 eq.) in DMF (final concentration $\sim 0.15 \mathrm{M}$ ). After 3 min, the reaction was quenched by addition of $1 \mathrm{M}$ aqueous triethylammonium bicarbonate (10 vol. eq.) The resulting crude solution was stirred for $30 \mathrm{~min}$ at $0{ }^{\circ} \mathrm{C}$ and then lyophilized. The crude material was purified by reverse phase HPLC (C18 column, $1-35 \% \mathrm{CH}_{3} \mathrm{CN}$ in $0.1 \mathrm{M} \mathrm{NEt}_{3}$ $\mathrm{HCO}_{3}, \mathrm{pH}$ 7.5) followed by lyophilization to afford the triphosphate as a white solid. TM and DM5 triphosphates were synthesized as described previously. 9,12

2OMe triphosphate: ${ }^{31} \mathrm{P}$ NMR $\left(162 \mathrm{MHz}, \mathrm{D}_{2} \mathrm{O}\right) \delta-5.90(\mathrm{~d}, J=21.2 \mathrm{~Hz}),-10.55(\mathrm{~d}, J=19.8)$, $-22.16(\mathrm{t}, J=20.7 \mathrm{~Hz})$. 3OMe triphosphate: ${ }^{31} \mathrm{P}$ NMR $\left(162 \mathrm{MHz}, \mathrm{D}_{2} \mathrm{O}\right) \delta-10.32(\mathrm{~d}, J=19.9$ $\mathrm{Hz}),-10.76$ (d, $J=20.4),-22.83(\mathrm{t}, J=19.9 \mathrm{~Hz}) .40 \mathrm{Me}$ triphosphate: ${ }^{31} \mathrm{P}$ NMR $(162 \mathrm{MHz}$, $\left.\mathrm{D}_{2} \mathrm{O}\right) \delta-10.39(\mathrm{~d}, J=19.9 \mathrm{~Hz}),-10.71(\mathrm{~d}, J=20.1),-22.82(\mathrm{t}, J=19.9 \mathrm{~Hz})$. DMO triphosphate: ${ }^{31} \mathrm{P}$ NMR $\left(162 \mathrm{MHz}, \mathrm{D}_{2} \mathrm{O}\right) \delta-6.01(\mathrm{~d}, J=21.2 \mathrm{~Hz}),-10.52(\mathrm{~d}, J=19.9),-22.21$ (t, $J=20.6 \mathrm{~Hz})$. MMO1 triphosphate: ${ }^{31} \mathrm{P}$ NMR $\left(162 \mathrm{MHz}, \mathrm{D}_{2} \mathrm{O}\right) \delta-9.35(\mathrm{~d}, J=19.3 \mathrm{~Hz}),-10.67$ (d, $J=20.1),-22.68$ (t, $J=20.1 \mathrm{~Hz})$. MMO2 triphosphate: ${ }^{31} \mathrm{P}$ NMR $\left(162 \mathrm{MHz}, \mathrm{D}_{2} \mathrm{O}\right) \delta-5.91$ (d, $J=21.2 \mathrm{~Hz}),-10.56$ (d, $J=19.6),-22.17$ (t, $J=20.6 \mathrm{~Hz})$. MM1 triphosphate: ${ }^{31} \mathrm{P}$ NMR (162 $\left.\mathrm{MHz}, \mathrm{D}_{2} \mathrm{O}\right) \delta-8.03(\mathrm{bs}),-10.63$ (d, $\left.J=19.9\right),-22.48(\mathrm{t}, J=20.4 \mathrm{~Hz}$ ). 


\section{Gel-Based Kinetic Assay}

Primer oligonucleotides were 5'-radiolabeled with T4 polynucleotide kinase (New England Biolabs) and $\left[\gamma^{33} \mathrm{P}\right]$-ATP (GE Biosciences). Primers were annealed to template oligonucleotides in the reaction buffer by heating to $90^{\circ} \mathrm{C}$ followed by slow cooling to ambient temperature. Assay conditions included $40 \mathrm{nM}$ primer/template, $0.1-1.3 \mathrm{nM}$ enzyme (either Kf or Kf R668A), $50 \mathrm{mM}$ Tris-HCl, pH 7.5, $10 \mathrm{mM} \mathrm{MgCl}_{2}, 1 \mathrm{mM}$ DTT, and $50 \mu \mathrm{g} / \mathrm{mL}$ acetylated BSA. The reactions were carried out by combining the DNA-enzyme mixture with an equal volume $(5 \mu \mathrm{L})$ of $2 \times \mathrm{dNTP}$ stock solution, incubating at $25^{\circ} \mathrm{C}$ for $1-10 \mathrm{~min}$, and quenching by the addition of $20 \mu \mathrm{L}$ of loading dye (95\% formamide, $20 \mathrm{mM}$ EDTA, and sufficient amounts of bromophenol blue and xylene cyanole). The reaction mixtures were resolved by $15 \%$ polyacrylamide and $8 \mathrm{M}$ urea denaturing gel electrophoresis, and radioactivity was quantified using a PhosphorImager (Molecular Dynamics) and ImageQuant software. The Michaelis-Menten equation was fit to a plot $k_{\text {obs }}$ versus triphosphate concentration using the program Kaleidagraph (Synergy Software). The data presented are averages of three independent determinations.

\section{Supplementary Material}

Refer to Web version on PubMed Central for supplementary material.

\section{Acknowledgements}

Funding was provided by the National Institutes of Health (GM60005).

\section{References}

1. Henry AA, Romesberg FE. Curr Opin Chem Biol 2003;7:727-733. [PubMed: 14644182]

2. Piccirilli JA, Krauch T, Moroney SE, Benner SA. Nature 1990;343:33-37. [PubMed: 1688644]

3. Sismour AM, Benner SA. Nucleic Acids Res 2005;33:5640-5646. [PubMed: 16192575]

4. Hirao I. Curr Opin Chem Biol 2006;10:622-627. [PubMed: 17035074]

5. Hirao I, Kimoto M, Mitsui T, Fujiwara T, Kawai R, Sato A, Harada Y, Yokoyama S. Nat Methods 2006;3:729-735. [PubMed: 16929319]

6. Henry AA, Olsen AG, Matsuda S, Yu C, Geierstanger BH, Romseberg FE. J Am Chem Soc 2004;126:6923-6931. [PubMed: 15174862]

7. Henry AA, Yu C, Romesberg FE. J Am Chem Soc 2003;125:9638-9646. [PubMed: 12904030]

8. Hwang GT, Romesberg FE. Nucleic Acids Res 2006;34:2037-2045. [PubMed: 16617144]

9. Matsuda S, Henry AA, Romesberg FE. J Am Chem Soc 2006;128:6369-6375. [PubMed: 16683801]

10. McMinn DL, Ogawa AK, Wu Y, Liu J, Schultz PG, Romesberg FE. J Am Chem Soc 1999;121:1158511586.

11. Ogawa AK, Wu Y, Berger M, Schultz PG, Romesberg FE. J Am Chem Soc 2000;122:8803-8804.

12. Ogawa AK, Wu Y, McMinn DL, Liu J, Schultz PG, Romesberg FE. J Am Chem Soc 2000;122:32743287.

13. Tae EL, Wu YQ, Xia G, Schultz PG, Romesberg FE. J Am Chem Soc 2001;123:7439-7440. [PubMed: 11472182]

14. Yu C, Henry AA, Romesberg FE, Schultz PG. Angew Chem Int Ed 2002;41:3841-3844.

15. Hirao I, Harada Y, Kimoto M, Mitsui T, Fujiwara T, Yokoyama S. J Am Chem Soc 2004;126:1329812305. [PubMed: 15479084]

16. Chiaramonte M, Moore CL, Kincaid K, Kuchta RD. Biochemistry 2003;42:10472-10481. [PubMed: 12950174]

17. Kincaid K, Beckman J, Zivkovic A, Halcomb RL, Engels JW, Kuchta RD. Nucleic Acids Res 2005;33:2620-2628. [PubMed: 15879351]

18. Matray TJ, Kool ET. Nature 1999;399:704-708. [PubMed: 10385125]

$J$ Am Chem Soc. Author manuscript; available in PMC 2008 August 29. 
19. Morales JC, Kool ET. J Am Chem Soc 1999;121:2323-2324.

20. Zhang X, Lee I, Berdis AJ. Biochemistry 2005;44:13101-13110. [PubMed: 16185078]

21. Zhang X, Lee I, Zhou X, Berdis AJ. J Am Chem Soc 2006;128:143-149. [PubMed: 16390141]

22. Kim Y, Leconte AM, Hari Y, Romesberg FE. Angew Chem Int Ed Engl 2006;45:7809-7812. [PubMed: 17075934]

23. Leconte AM, Matsuda S, Hwang GT, Romesberg FE. Angew Chem Int Ed Engl 2006;45:4326-4329. [PubMed: 16733840]

24. Matsuda S, Romesberg FE. J Am Chem Soc 2004;126:14419-14427. [PubMed: 15521761]

25. Adelfinskaya O, Nashine VC, Bergstrom DE, Davisson VJ. J Am Chem Soc 2005;127:16000-16001. [PubMed: 16287267]

26. Moran S, Ren RXF, Rumney SI, Kool ET. J Am Chem Soc 1997;119:2056-2057.

27. Spratt TE. Biochemistry 2001;40:2647-2652. [PubMed: 11258875]

28. Morales JC, Kool ET. Biochemistry 2000;39:12979-12988. [PubMed: 11041863]

29. Li Y, Waksman G. Protein Sci 2001;10:1225-1233. [PubMed: 11369861]

30. Meyer AS, Blandino M, Spratt TE. J Biol Chem 2004;279:33043-33046. [PubMed: 15210707]

31. Becucci M, Pietraperzia G, Pasquini M, Piani G, Zoppi A, Chelli R, Castellucci E, Demtroeder W. J Chem Phys 2004;120:5601-5607. [PubMed: 15267436]

32. Reimann K, Buchhold HD, Brutschy B, Tarakeshwar P, Kim KS. J Chem Phys 2002;117:8805-8822.

33. Nobeli I, Yeoh SL, Price SL, Taylor R. Chem Phys Lett 1997;280:196-202.

34. Ribblett JW, Sinclair WE, Borst DR, Yi JT, Pratt DW. J Phys Chem A 2006;110:1478-1483. [PubMed: 16435807]

35. Kuchta RD, Benkovic P, Benkovic SJ. Biochemistry 1988;27:6716-6725. [PubMed: 3058205]

36. Minnick DT, Bebenek K, Osheroff WP, Turner RM Jr, Astatke M, Liu T, Kunkel TA, Joyce CM. J Biol Chem 1999;274:3067-3075. [PubMed: 9915846]

37. Summerer D, Rudinger NZ, Detmer I, Marx A. Angew Chem Int Ed Engl 2005;44:4712-4715. [PubMed: 15995989]

38. Potapova O, Chan C, DeLucia AM, Helquist SA, Kool ET, Grindley ND, Joyce CM. Biochemistry 2006;45:890-898. [PubMed: 16411765]

39. Mitsui T, Kimoto M, Sato A, Yokoyama S, Hirao I. Bioorg Med Chem Lett 2003;13:4515-4518. [PubMed: 14643359]

40. Mitsui T, Kitamura A, Kimoto M, To T, Sato A, Hirao I, Yokoyama S. J Am Chem Soc 2003;125:5298-5307. [PubMed: 12720441]

41. Arnett EM, Wu CY. J Am Chem Soc 1960;82:4999-5000. 
(a)<smiles>O=[N+]([O-])c1ccccc1</smiles>

BEN<smiles>Cc1ccccc1[N+](=O)[O-]</smiles>

MM1<smiles>Cc1ccc([N+](=O)[O-])c(C)c1</smiles>

DM5<smiles>Cc1cc(C)c([N+](=O)[O-])cc1C</smiles>

TM<smiles>O=[N+]([O-])c1cccc(F)c1</smiles>

3FB

(b)<smiles>COc1ccccc1[N+](=O)[O-]</smiles>

2OMe<smiles>COc1ccc([N+](=O)[O-])c(OC)c1</smiles>

DMO<smiles>COc1cccc([N+](=O)[O-])c1</smiles>

30Me<smiles>COc1ccc([N+](=O)[O-])c(C)c1</smiles>

MMO1<smiles>COc1ccc([N+](=O)[O-])cc1</smiles>

40Me<smiles>COc1cc(C)ccc1[N+](=O)[O-]</smiles>

MMO2

Figure 1.

(a) Unnatural nucleobases previously reported. (b) Methoxy substituted benzene analogs used in this study. 


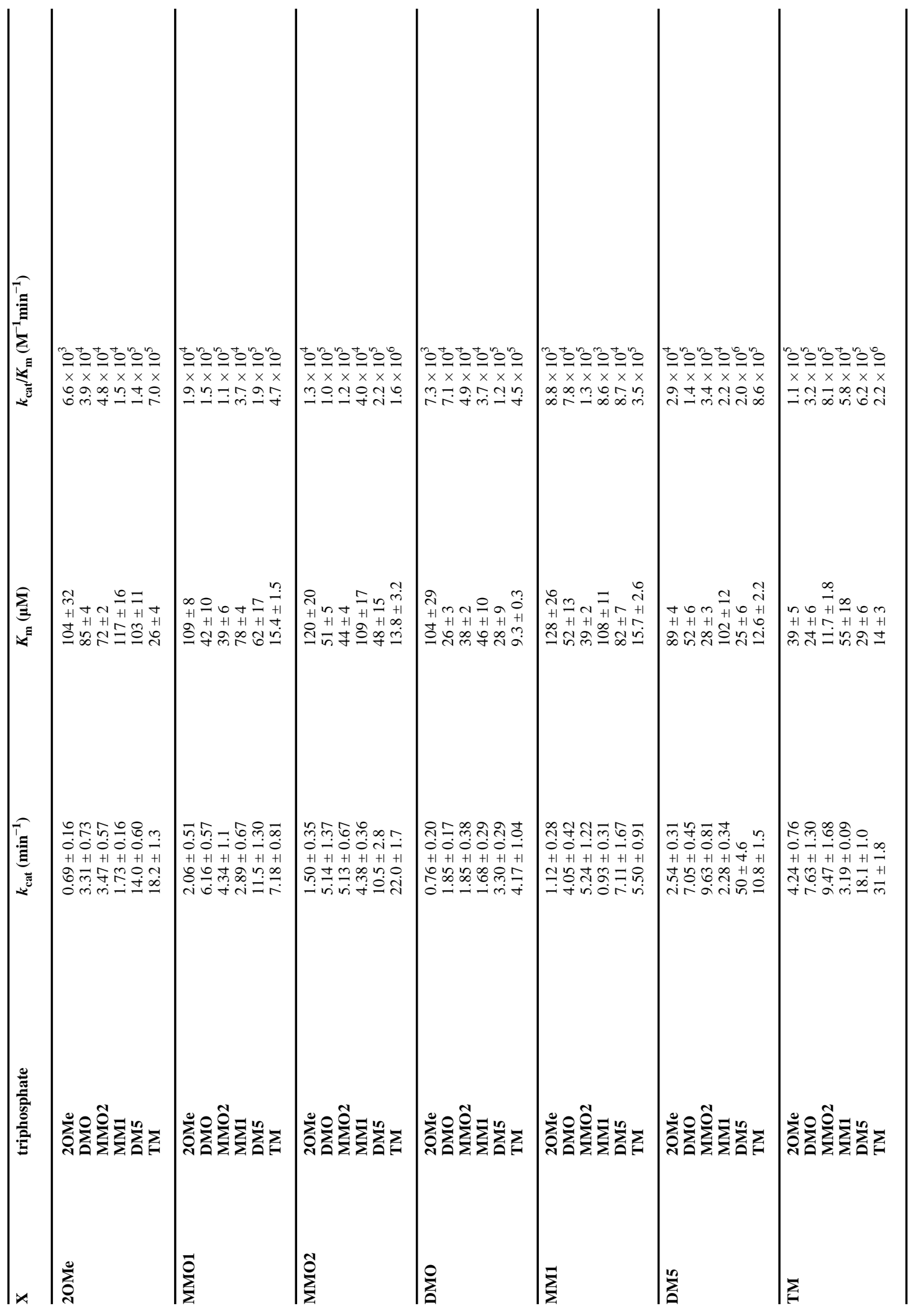


Table 2

Incorporation of unnatural and natural triphosphates opposite unnatural bases in the template ${ }^{a}$

5'-d(TAATACGACTCACTATAGGGAGA)

3'-d(ATTATGCTGAGTGATATCCCTCTXGCTAGGTTACGGCAGGATCGC)

\begin{tabular}{|c|c|c|c|c|}
\hline $\mathbf{X}$ & triphosphate & $k_{\text {cat }}\left(\min ^{-1}\right)$ & $K_{\mathrm{m}}(\mu \mathrm{M})$ & $k_{\mathrm{cat}} / K_{\mathrm{m}}\left(\mathrm{M}^{-1} \min ^{-1}\right)$ \\
\hline $20 \mathrm{Me}$ & $\begin{array}{l}\mathrm{A} \\
\mathrm{C} \\
\mathrm{G} \\
\mathrm{T}\end{array}$ & $\begin{array}{l}3.78 \pm 0.17 \\
\mathrm{nd}^{b} \\
\mathrm{nd}^{b} \\
\mathrm{nd}^{b}\end{array}$ & $\begin{array}{l}44 \pm 11 \\
\operatorname{nd}^{b} \\
\operatorname{nd}^{b} \\
\text { nd }^{b}\end{array}$ & $\begin{array}{l}8.6 \times 10^{4} \\
<1.0 \times 10^{3} \\
<1.0 \times 10^{3} \\
<1.0 \times 10^{3}\end{array}$ \\
\hline$\overline{30 M e}$ & $\begin{array}{l}\text { A } \\
\text { C } \\
\text { G } \\
\text { T }\end{array}$ & $\begin{array}{l}1.77 \pm 0.22 \\
0.29 \pm 0.04 \\
\mathrm{nd}^{b} \\
0.33 \pm 0.08\end{array}$ & $\begin{array}{l}32 \pm 10 \\
168 \pm 28 \\
\text { nd }^{b} \\
130 \pm 12\end{array}$ & $\begin{array}{l}5.5 \times 10^{4} \\
1.7 \times 10^{3} \\
<1.0 \times 10^{3} \\
2.5 \times 10^{3}\end{array}$ \\
\hline$\overline{4 O M e}$ & $\begin{array}{l}\mathrm{A} \\
\mathrm{C} \\
\mathrm{G} \\
\mathrm{T}\end{array}$ & $\begin{array}{l}2.96 \pm 0.25 \\
\mathrm{nd}^{b} \\
\mathrm{nd}^{b} \\
3.03 \pm 0.23\end{array}$ & $\begin{array}{l}25 \pm 7 \\
\text { nd }^{b} \\
\text { nd }^{b} \\
95 \pm 18\end{array}$ & $\begin{array}{l}1.2 \times 10^{5} \\
<1.0 \times 10^{3} \\
<1.0 \times 10^{3} \\
3.2 \times 10^{4}\end{array}$ \\
\hline$\overline{M M O 1}$ & $\begin{array}{l}\mathrm{A} \\
\mathrm{C} \\
\mathrm{G} \\
\mathrm{T}\end{array}$ & $\begin{array}{l}4.50 \pm 0.40 \\
\mathrm{nd}^{b} \\
\mathrm{nd}^{b} \\
0.28 \pm 0.02\end{array}$ & $\begin{array}{l}25 \pm 8 \\
\mathrm{nd}^{b} \\
\mathrm{nd}^{b} \\
128 \pm 6\end{array}$ & $\begin{array}{l}1.8 \times 10^{5} \\
<1.0 \times 10^{3} \\
<1.0 \times 10^{3} \\
2.2 \times 10^{3}\end{array}$ \\
\hline MMO2 & $\begin{array}{l}\mathrm{A} \\
\mathrm{C} \\
\mathrm{G} \\
\mathrm{T}\end{array}$ & $\begin{array}{l}3.27 \pm 0.33 \\
\mathrm{nd}^{b} \\
\mathrm{nd}^{b} \\
\mathrm{nd}^{b}\end{array}$ & $\begin{array}{l}32 \pm 4 \\
\operatorname{nd}^{b} \\
\operatorname{nd}^{b} \\
\operatorname{nd}^{b}\end{array}$ & $\begin{array}{l}1.0 \times 10^{5} \\
<1.0 \times 10^{3} \\
<1.0 \times 10^{3} \\
<1.0 \times 10^{3}\end{array}$ \\
\hline$\overline{\text { DMO }}$ & $\begin{array}{l}\mathrm{A} \\
\mathrm{C} \\
\mathrm{G} \\
\mathrm{T}\end{array}$ & $\begin{array}{l}1.08 \pm 0.15 \\
\mathrm{nd}^{b} \\
\mathrm{nd}^{b} \\
0.14 \pm 0.03\end{array}$ & $\begin{array}{l}13 \pm 1.3 \\
\text { nd }^{b} \\
\text { nd }^{b} \\
57 \pm 15\end{array}$ & $\begin{array}{l}8.3 \times 10^{4} \\
<1.0 \times 10^{3} \\
<1.0 \times 10^{3} \\
2.5 \times 10^{3}\end{array}$ \\
\hline
\end{tabular}

${ }^{a}$ See Experimental Section for details.

${ }^{b}$ Reaction was too inefficient for $k_{\mathrm{cat}}$ and $K_{\mathrm{M}}$ to be determined independently. 
Table 3

Rates of correct extension of unnatural base pairs ${ }^{a}$

5'-d(TAATACGACTCACTATAGGGAGAY)

3'-d(ATTATGCTGAGTGATATCCCTCTXGCTAGGTTACGGCAGGATCGC)

\begin{tabular}{|c|c|c|c|c|}
\hline $\mathbf{X}$ & $\mathbf{Y}$ & $k_{\text {cat }}\left(\min ^{-1}\right)$ & $K_{\mathrm{m}}(\mu \mathrm{M})$ & $k_{\mathrm{cat}} / K_{\mathrm{m}}\left(\mathrm{M}^{-1} \min ^{-1}\right)$ \\
\hline 2OMe & $\begin{array}{l}\text { 2OMe } \\
\text { 3OMe } \\
\text { 4OMe } \\
\text { DMO } \\
\text { MMO1 } \\
\text { MMO2 } \\
\text { MM1 } \\
\text { DM5 } \\
\text { TM }\end{array}$ & $\begin{array}{l}\mathrm{nd}^{b} \\
0.27 \pm 0.02 \\
0.96 \pm 0.24 \\
0.30 \pm 0.10 \\
0.21 \pm 0.03 \\
0.38 \pm 0.14 \\
\mathrm{nd}^{b} \\
0.47 \pm 0.15 \\
0.40 \pm 0.09\end{array}$ & $\begin{array}{l}\text { nd }^{b} \\
173 \pm 11 \\
209 \pm 61 \\
178 \pm 77 \\
165 \pm 51 \\
170 \pm 39 \\
\text { nd }^{b} \\
231 \pm 48 \\
173 \pm 40\end{array}$ & $\begin{array}{l}<1.0 \times 10^{3} \\
1.6 \times 10^{3} \\
4.6 \times 10^{3} \\
1.7 \times 10^{3} \\
1.3 \times 10^{3} \\
2.2 \times 10^{3} \\
<1.0 \times 10^{3} \\
2.0 \times 10^{3} \\
2.3 \times 10^{3}\end{array}$ \\
\hline $30 \mathrm{Me}$ & $\begin{array}{l}\text { 2OMe } \\
\text { 3OMe } \\
\text { 4OMe } \\
\text { DMO } \\
\text { MMO1 } \\
\text { MMO2 } \\
\text { MM1 } \\
\text { DM5 } \\
\text { TM }\end{array}$ & $\begin{array}{l}3.12 \pm 0.82 \\
\mathrm{nd}^{b} \\
0.79 \pm 0.15 \\
3.14 \pm 0.31 \\
0.22 \pm 0.08 \\
4.95 \pm 1.39 \\
\mathrm{nd}^{b} \\
0.32 \pm 0.07 \\
0.18 \pm 0.05\end{array}$ & $\begin{array}{l}112 \pm 29 \\
\text { nd }^{b} \\
218 \pm 53 \\
132 \pm 21 \\
175 \pm 74 \\
160 \pm 53 \\
\text { nd }^{2} \\
138 \pm 43 \\
144 \pm 25\end{array}$ & $\begin{array}{l}2.8 \times 10^{4} \\
<1.0 \times 10^{3} \\
3.6 \times 10^{3} \\
2.4 \times 10^{4} \\
1.3 \times 10^{3} \\
3.1 \times 10^{4} \\
<1.0 \times 10^{3} \\
2.3 \times 10^{3} \\
1.3 \times 10^{3}\end{array}$ \\
\hline 4OMe & $\begin{array}{l}\text { 2OMe } \\
\text { 3OMe } \\
\text { 4OMe } \\
\text { DMO } \\
\text { MMO1 } \\
\text { MMO2 } \\
\text { MM1 } \\
\text { DM5 } \\
\text { TM }\end{array}$ & $\begin{array}{l}2.49 \pm 0.83 \\
\text { nd }^{b} \\
\text { nd }^{b} \\
3.08 \pm 0.73 \\
\text { nd }^{2} \\
6.04 \pm 0.55 \\
\text { nd }^{b} \\
\text { nd }^{b} \\
\text { nd }^{b}\end{array}$ & $\begin{array}{l}162 \pm 11 \\
\text { nd }^{b} \\
\text { nd }^{b} \\
147 \pm 41 \\
\text { nd } b \\
127 \pm 30 \\
\text { nd }^{2} \\
\text { nd }^{b} \\
\text { nd }^{b}\end{array}$ & $\begin{array}{l}1.5 \times 10^{4} \\
<1.0 \times 10^{3} \\
<1.0 \times 10^{3} \\
2.1 \times 10^{4} \\
<1.0 \times 10^{3} \\
4.8 \times 10^{4} \\
<1.0 \times 10^{3} \\
<1.0 \times 10^{3} \\
<1.0 \times 10^{3}\end{array}$ \\
\hline MMO1 & $\begin{array}{l}20 M e \\
30 M e \\
40 M e \\
\text { DMO } \\
\text { MMO1 } \\
\text { MMO2 } \\
\text { MM1 } \\
\text { DM5 } \\
\text { TM }\end{array}$ & $\begin{array}{l}9.19 \pm 1.24 \\
0.68 \pm 0.12 \\
0.64 \pm 0.14 \\
6.52 \pm 0.77 \\
0.27 \pm 0.04 \\
6.88 \pm 1.24 \\
0.17 \pm 0.07 \\
0.56 \pm 0.14 \\
0.39 \pm 0.04\end{array}$ & $\begin{array}{l}86 \pm 3 \\
195 \pm 74 \\
172 \pm 39 \\
60 \pm 18 \\
125 \pm 35 \\
46 \pm 11 \\
168 \pm 43 \\
132 \pm 16 \\
144 \pm 34\end{array}$ & $\begin{array}{l}1.1 \times 10^{5} \\
3.5 \times 10^{3} \\
3.7 \times 10^{3} \\
1.1 \times 10^{5} \\
2.2 \times 10^{3} \\
1.5 \times 10^{5} \\
1.0 \times 10^{3} \\
4.2 \times 10^{3} \\
2.7 \times 10^{3}\end{array}$ \\
\hline MMO2 & $\begin{array}{l}\text { OMe } \\
\text { 3OMe } \\
\text { 4OMe } \\
\text { DMO } \\
\text { MMO1 } \\
\text { MMO2 } \\
\text { MM1 } \\
\text { DM5 } \\
\text { TM }\end{array}$ & $\begin{array}{l}0.44 \pm 0.11 \\
1.07 \pm 0.14 \\
1.83 \pm 0.66 \\
0.55 \pm 0.12 \\
0.50 \pm 0.13 \\
0.87 \pm 0.28 \\
0.36 \pm 0.20 \\
1.48 \pm 0.08 \\
0.98 \pm 0.23\end{array}$ & $\begin{array}{l}201 \pm 51 \\
243 \pm 37 \\
184 \pm 34 \\
147 \pm 24 \\
247 \pm 15 \\
165 \pm 47 \\
184 \pm 95 \\
148 \pm 24 \\
155 \pm 33\end{array}$ & $\begin{array}{l}2.2 \times 10^{3} \\
4.4 \times 10^{3} \\
9.9 \times 10^{3} \\
3.7 \times 10^{3} \\
2.0 \times 10^{3} \\
5.3 \times 10^{3} \\
2.0 \times 10^{3} \\
1.0 \times 10^{4} \\
6.3 \times 10^{3}\end{array}$ \\
\hline DMO & $\begin{array}{l}\text { 2OMe } \\
\text { 3OMe } \\
\text { 4OMe } \\
\text { DMO } \\
\text { MMO1 } \\
\text { MMO2 } \\
\text { MM1 } \\
\text { DM5 } \\
\text { TM }\end{array}$ & $\begin{array}{l}\mathrm{nd}^{b} \\
0.35 \pm 0.08 \\
0.37 \pm 0.04 \\
\mathrm{nd}^{b} \\
0.17 \pm 0.04 \\
0.47 \pm 0.11 \\
\mathrm{nd}^{b} \\
0.35 \pm 0.03 \\
0.34 \pm 0.02\end{array}$ & $\begin{array}{l}\mathrm{nd}^{b} \\
152 \pm 62 \\
163 \pm 42 \\
\mathrm{nd}^{b} \\
143 \pm 33 \\
158 \pm 22 \\
\mathrm{nd}^{b} \\
124 \pm 13 \\
99 \pm 14\end{array}$ & $\begin{array}{l}<1.0 \times 10^{3} \\
2.3 \times 10^{3} \\
2.3 \times 10^{3} \\
<1.0 \times 10^{3} \\
1.2 \times 10^{3} \\
3.0 \times 10^{3} \\
<1.0 \times 10^{3} \\
2.8 \times 10^{3} \\
3.4 \times 10^{3}\end{array}$ \\
\hline MM1 & $\begin{array}{l}\text { 2OMe } \\
\text { 3OMe } \\
40 M e \\
\text { DMO } \\
\text { MMO1 } \\
\text { MMO2 } \\
\text { MM1 }\end{array}$ & $\begin{array}{l}9.34 \pm 1.48 \\
0.40 \pm 0.02 \\
0.92 \pm 0.05 \\
5.90 \pm 1.19 \\
0.25 \pm 0.06 \\
7.18 \pm 0.39 \\
0.25 \pm 0.07\end{array}$ & $\begin{array}{l}124 \pm 14 \\
153 \pm 13 \\
153 \pm 25 \\
86 \pm 3 \\
92 \pm 10 \\
50 \pm 10 \\
173 \pm 100\end{array}$ & $\begin{array}{l}7.5 \times 10^{4} \\
2.6 \times 10^{3} \\
6.0 \times 10^{3} \\
6.9 \times 10^{4} \\
2.7 \times 10^{3} \\
1.4 \times 10^{5} \\
1.4 \times 10^{3}\end{array}$ \\
\hline
\end{tabular}


5'-d(TAATACGACTCACTATAGGGAGAY)

3'-d(ATTATGCTGAGTGATATCCCTCTXGCTAGGTTACGGCAGGATCGC)

\begin{tabular}{|c|c|c|c|c|}
\hline $\mathbf{X}$ & $\mathbf{Y}$ & $k_{\text {cat }}\left(\min ^{-1}\right)$ & $K_{\mathrm{m}}(\mu \mathrm{M})$ & $k_{\text {cat }} / K_{\mathrm{m}}\left(\mathrm{M}^{-1} \min ^{-1}\right)$ \\
\hline & $\begin{array}{l}\text { DM5 } \\
\text { TM }\end{array}$ & $\begin{array}{l}0.35 \pm 0.08 \\
0.54 \pm 0.07\end{array}$ & $\begin{array}{l}163 \pm 17 \\
168 \pm 46\end{array}$ & $\begin{array}{l}2.1 \times 10^{3} \\
3.2 \times 10^{3}\end{array}$ \\
\hline DM5 & $\begin{array}{l}\text { 2OMe } \\
\text { 3OMe } \\
\text { 40Me } \\
\text { DMO } \\
\text { MMO1 } \\
\text { MMO2 } \\
\text { MM1 } \\
\text { DM5 } \\
\text { TM }\end{array}$ & $\begin{array}{l}7.30 \pm 0.54 \\
1.23 \pm 0.33 \\
1.29 \pm 0.36 \\
5.44 \pm 0.49 \\
0.48 \pm 0.13 \\
6.07 \pm 0.85 \\
0.23 \pm 0.09 \\
6.5 \pm 1.1 \\
1.04 \pm 0.18\end{array}$ & $\begin{array}{l}57 \pm 13 \\
121 \pm 30 \\
104 \pm 35 \\
54 \pm 5 \\
121 \pm 10 \\
18.6 \pm 2.5 \\
220 \pm 91 \\
161 \pm 17 \\
95 \pm 10\end{array}$ & $\begin{array}{l}1.3 \times 10^{5} \\
1.0 \times 10^{4} \\
1.2 \times 10^{4} \\
1.0 \times 10^{5} \\
4.0 \times 10^{3} \\
3.3 \times 10^{5} \\
1.1 \times 10^{3} \\
4.0 \times 10^{4} \\
1.1 \times 10^{4}\end{array}$ \\
\hline $\mathbf{T M}$ & $\begin{array}{l}\text { 2OMe } \\
\text { 3OMe } \\
\text { 4OMe } \\
\text { DMO } \\
\text { MMO1 } \\
\text { MMO2 } \\
\text { MM1 } \\
\text { DM5 } \\
\text { TM }\end{array}$ & $\begin{array}{l}12.0 \pm 2.7 \\
3.79 \pm 0.09 \\
3.37 \pm 0.30 \\
4.13 \pm 0.60 \\
1.51 \pm 0.27 \\
10.1 \pm 1.4 \\
0.62 \pm 0.11 \\
2.74 \pm 0.54 \\
7.9 \pm 1.4\end{array}$ & $\begin{array}{l}12.4 \pm 1.5 \\
92 \pm 17 \\
89 \pm 19 \\
13.1 \pm 2.9 \\
85 \pm 24 \\
7.9 \pm 0.97 \\
108 \pm 3 \\
92 \pm 18 \\
152 \pm 32\end{array}$ & $\begin{array}{l}9.7 \times 10^{5} \\
4.1 \times 10^{4} \\
3.8 \times 10^{4} \\
3.2 \times 10^{5} \\
1.8 \times 10^{4} \\
1.3 \times 10^{6} \\
5.7 \times 10^{3} \\
3.0 \times 10^{4} \\
5.2 \times 10^{4}\end{array}$ \\
\hline BEN & $\begin{array}{l}\text { 2OMe } \\
\text { 3OMe } \\
\text { 4OMe } \\
\text { DMO } \\
\text { MMO1 } \\
\text { MMO2 } \\
\text { MM1 } \\
\text { DM5 } \\
\text { TM }\end{array}$ & $\begin{array}{l}1.49 \pm 0.35 \\
\mathrm{nd}^{b} \\
\mathrm{nd}^{b} \\
2.42 \pm 0.41 \\
\mathrm{nd}^{b} \\
4.05 \pm 0.65 \\
\mathrm{nd}^{b} \\
\mathrm{nd}^{b} \\
\mathrm{nd}^{b}\end{array}$ & $\begin{array}{l}272 \pm 28 \\
\mathrm{nd}^{b} \\
\mathrm{nd}^{b} \\
191 \pm 44 \\
\mathrm{nd}^{b} \\
233 \pm 21 \\
\operatorname{nd}^{b} \\
\operatorname{nd}^{b} \\
\operatorname{nd}^{b}\end{array}$ & $\begin{array}{l}5.5 \times 10^{3} \\
<1.0 \times 10^{3} \\
<1.0 \times 10^{3} \\
1.3 \times 10^{4} \\
<1.0 \times 10^{3} \\
1.7 \times 10^{4} \\
<1.0 \times 10^{3} \\
<1.0 \times 10^{3} \\
<1.0 \times 10^{3}\end{array}$ \\
\hline
\end{tabular}

$a_{\text {See Experimental Section for details. }}$

${ }^{b}$ Reaction was too inefficient for $k_{\text {cat }}$ and $K_{\mathrm{M}}$ to be determined independently. 
Table 4

Rates of mispair extension ${ }^{a}$

5'-d(TAATACGACTCACTATAGGGAGAY)

3'-d(ATTATGCTGAGTGATATCCCTCTXGCTAGGTTACGGCAGGATCGC)

\begin{tabular}{|c|c|c|c|c|}
\hline $\bar{X}$ & $\mathbf{Y}$ & $k_{\text {cat }}\left(\min ^{-1}\right)$ & $K_{\mathrm{m}}(\mu \mathrm{M})$ & $k_{\text {cat }} / K_{\mathrm{m}}\left(\mathrm{M}^{-1} \mathrm{~min}^{-1}\right)$ \\
\hline MM1 & $\mathrm{A}$ & $5.61 \pm 0.38$ & $29 \pm 6$ & $1.9 \times 10^{5}$ \\
\hline DM5 & A & $7.29 \pm 1.75$ & $27 \pm 6$ & $2.7 \times 10^{5}$ \\
\hline MMO1 & $\mathrm{A}$ & $9.48 \pm 0.69$ & $23 \pm 2$ & $4.1 \times 10^{5}$ \\
\hline MMO2 & A & $8.65 \pm 0.89$ & $187 \pm 17$ & $4.6 \times 10^{4}$ \\
\hline TM & A & $8.13 \pm 1.59$ & $15.5 \pm 2.2$ & $5.2 \times 10^{5}$ \\
\hline A & 2OMe & $\mathrm{nd}^{b}$ & nd $b$ & $<1.0 \times 10^{3}$ \\
\hline $\mathrm{G}$ & 2OMe & $\mathrm{nd}^{b}$ & $\mathrm{nd}^{b}$ & $<1.0 \times 10^{3}$ \\
\hline $\mathrm{C}$ & 2OMe & $0.40 \pm 0.15$ & $111 \pm 37$ & $3.6 \times 10^{3}$ \\
\hline $\mathrm{T}$ & 2OMe & $0.39 \pm 0.09$ & $87 \pm 13$ & $4.5 \times 10^{3}$ \\
\hline A & DMO & $\mathrm{nd}^{b}$ & nd $^{b}$ & $<1.0 \times 10^{3}$ \\
\hline G & DMO & $\mathrm{nd}^{b}$ & $\mathrm{nd}^{b}$ & $<1.0 \times 10^{3}$ \\
\hline $\mathrm{C}$ & DMO & $1.31 \pm 0.23$ & $69 \pm 11$ & $1.9 \times 10^{4}$ \\
\hline $\mathrm{T}$ & DMO & $0.92 \pm 0.04$ & $59 \pm 6$ & $1.6 \times 10^{4}$ \\
\hline A & MMO2 & $\mathrm{nd}^{b}$ & $\mathrm{nd}^{b}$ & $<1.0 \times 10^{3}$ \\
\hline $\mathrm{G}$ & MMO2 & $\mathrm{nd}^{b}$ & $\mathrm{nd}^{b}$ & $<1.0 \times 10^{3}$ \\
\hline $\mathrm{C}$ & MMO2 & $0.67 \pm 0.25$ & $134 \pm 32$ & $5.0 \times 10^{3}$ \\
\hline $\mathrm{T}$ & MMO2 & $2.11 \pm 0.63$ & $80 \pm 13$ & $2.6 \times 10^{4}$ \\
\hline
\end{tabular}

$a_{\text {See Experimental Section for details. }}$

${ }^{b}$ Reaction was too inefficient for $k_{\mathrm{cat}}$ and $K_{\mathrm{M}}$ to be determined independently. 
Table 5

Rates of correct extension by R668A Kf mutant ${ }^{a}$

5'-d(TAATACGACTCACTATAGGGAGAY)

3'-d(ATTATGCTGAGTGATATCCCTCTXGCTAGGTTACGGCAGGATCGC)

\begin{tabular}{lllll}
\hline $\mathbf{X}$ & $\mathbf{Y}$ & $\boldsymbol{k}_{\text {cat }}\left(\mathbf{m i n}^{-\mathbf{1}}\right)$ & $\boldsymbol{K}_{\mathbf{m}}(\boldsymbol{\mu M})$ & $\boldsymbol{k}_{\text {cat }} / \boldsymbol{K}_{\mathrm{m}}\left(\mathbf{M}^{-\mathbf{1}} \mathbf{m i n}^{-\mathbf{1}}\right)$ \\
\hline T & A & $9.09 \pm 1.69$ & $29 \pm 6$ & $3.1 \times 10^{5}$ \\
TM & MMO2 & $2.31 \pm 0.79$ & $63 \pm 9$ & $3.7 \times 10^{4}$ \\
TM & DM5 & $0.60 \pm 0.09$ & $44 \pm 3$ & $1.4 \times 10^{4}$ \\
\hline
\end{tabular}

${ }^{a}$ See Experimental Section for details. 